Keywords: oropharyngeal squamous cell carcinomas; human papillomavirus; surgery; prognosis; head and neck cancer; risk model; recursive partitioning analysis

\title{
Human papillomavirus association is the most important predictor for surgically treated patients with oropharyngeal cancer
}

Steffen Wagner ${ }^{1,8}$, Claus Wittekindt ${ }^{1,8}$, Shachi Jenny Sharma ${ }^{1}$, Nora Wuerdemann ${ }^{1}$, Theresa Jüttner ${ }^{1}$, Miriam Reuschenbach ${ }^{2,3}$, Elena-Sophie Prigge ${ }^{2,3}$, Magnus von Knebel Doeberitz ${ }^{2,3}$, Stefan Gattenlöhner ${ }^{4}$, Ernst Burkhardt ${ }^{5,6,7}$, Jörn Pons-Kühnemann ${ }^{5,9}$ and Jens Peter Klussmann *,1,9

${ }^{1}$ Department of Otorhinolaryngology, Head and Neck Surgery, University of Giessen, Giessen DE-35392, Germany; ${ }^{2}$ Department of Applied Tumour Biology, Institute of Pathology, University Hospital Heidelberg, Heidelberg D-69120, Germany; ${ }^{3}$ Clinical Cooperation Unit Applied Tumour Biology, German Cancer Research Centre (DKFZ), Heidelberg D-69120, Germany; ${ }^{4}$ Department of Pathology, University of Giessen, Giessen DE-35392, Germany; ${ }^{5}$ Department of Medical Statistics, Institute of Medical Informatics, University of Giessen, Giessen DE-35392, Germany; ${ }^{6}$ Tumour Centre, University of Giessen, Giessen DE-35392, Germany and ${ }^{7}$ Hesse Cancer Registry, Frankfurt DE-60439, Germany

Background: Upfront surgery is a valuable treatment option for oropharyngeal squamous cell carcinoma (OPSCC) and risk stratification is emerging for treatment de-escalation in human papillomavirus (HPV)-related OPSCC. Available prognostic models are either based on selected, mainly non-surgically treated cohorts. Therefore, we investigated unselected OPSCC treated with predominantly upfront surgery.

Methods: All patients diagnosed with OPSCC and treated with curative intent between 2000 and $2009(n=359)$ were included. HPV association was determined by HPV-DNA detection and $\mathrm{p} 16^{\mathrm{INK} 4 \mathrm{a}}$ immunohistochemistry. Predictors with significant impact on overall survival (OS) in univariate analysis were included in recursive partitioning analysis.

Results: Risk models generated from non-surgically treated patients showed low discrimination in our cohort. A new model developed for unselected patients predominantly treated with upfront surgery separates low-, intermediate- and high-risk patients with significant differences in 5-year OS $(86 \%, 53 \%$ and $19 \%, P<0.001$, respectively). HPV status is the most important parameter followed by T-stage in HPV-related and performance status in HPV-negative OPSCC. HPV status and ECOG remained important parameters in risk models for patients treated with or without surgery.

Conclusions: Regardless of treatment strategies, HPV status is the strongest predictor of survival in unselected OPSCC patients. The proposed risk models are suitable to discriminate risk groups in unselected OPSCC patients treated with upfront surgery, which has substantial impact for design and interpretation of de-escalation trials.

Rising incidence rates of oropharyngeal squamous cell carcinoma (OPSCC) due to infections with carcinogenic human papillomavirus (HPV) have been reported over the last decades (Chaturvedi et al, 2011; Gillison et al, 2015; Tinhofer et al, 2015). The estimated number of newly diagnosed annual cases of HPV-related head and neck cancer in Europe is 15230 for males and females

\footnotetext{
${ }^{\star}$ Correspondence: Professor Dr JP Klussmann; E-mail: jens.p.klussmann@hno.med.uni-giessen.de

${ }^{8}$ These authors contributed equally as first authors.

${ }^{9}$ These authors contributed equally as senior authors.
}

Received 19 January 2017; revised 12 April 2017; accepted 12 April 2017; published online 4 May 2017

(C) 2017 Cancer Research UK. All rights reserved 0007-0920/17 
(Stanley, 2012). Projections for HPV-related OPSCC expect to exceed the incidence of cervical cancer in the United States and Western Europe in the near future (Chaturvedi et al, 2011).

HPV-related OPSCCs compose an independent tumour type with regard to cellular, biologic as well as clinical characteristics (Klussmann et al, 2001, 2003b; Hayes, 2015; Vokes et al, 2015; Maxwell et al, 2016). Retrospective and prospective studies show that patients suffering from HPV-related OPSCC have significantly better local-regional control but advanced $\mathrm{N}$-stage compared to patients with HPV-negative OPSCC (Ritchie et al, 2003; Ang et al, 2010; Fakhry et al, 2014; Keane et al, 2015). However, out of clinical studies OPSCC patients are still treated irrespective of the HPV status. In locally advanced disease, treatment strategies mainly consist of concurrent chemoradiotherapy or surgery followed by adjuvant radiation therapy, combined with chemotherapy according to risk factors (National Comprehensive Cancer Network; http://www.nccn.org). To date, no treatment modality has been identified as more effective, and no predictive factors guide treatment decisions. Therefore, treatment strategies are diverse and the choice between surgical and non-surgical approaches depends on regional preference to a large extend. However, due to favourable outcome after chemoradiotherapy in HPV-associated OPSCC and lack of evidence for the benefit of surgery in OPSCC, the management with ablative surgery has been questioned (Lybak et al, 2017). On the other hand, late toxicity after definitive chemoradiotherapy of squamous cell carcinoma of the head and neck patients has come into the focus. Therefore, several prospective randomised trials are conducted, to investigate whether treatment de-escalation can be achieved without impairment of disease control for low-risk patients with OPSCC (Mirghani et al, 2015).

Several risk stratification models for OPSCC have been published, but they are based on clinical studies with highly selected patients, or have been generated from cohorts with primary chemoradiotherapy as the preferred treatment regime (Ang et al, 2010; Granata et al, 2012; Rietbergen et al, 2013, 2015, Rios Velazquez et al, 2014). Therefore, these proposed risk models may be unsuited for patient cohorts treated with upfront surgery, which still is the standard treatment strategy in many countries. The aim of this study was to test whether the published models are suitable for risk stratification in an unselected cohort treated with upfront surgery and further, to propose a modified prognostic model for this group of patients developed by recursive partitioning analysis (RPA).

\section{MATERIALS AND METHODS}

Subjects and material. All patients diagnosed with primary cancers of the oropharynx (C09, C10, International Classification of Diseases for Oncology) treated at the Department of Oto-RhinoLaryngology, Head and Neck Surgery of the University of Giessen, Germany between 2000 and $2009(n=396)$ were included in accordance to the regional ethics committee. Exclusion criteria for the study were the absence of written informed consent and unavailable formalin-fixed, paraffin-embedded (FFPE) samples of pre-therapeutic tumour tissue. Patients were prospectively recorded by the Giessen cancer registry database (GTDS). Survival data for all patients were obtained by patient's files and residents registration office on a regular basis.

Therapy and risk factors. Tumours were classified by pathological stages (pTNM) or clinical stages (cTNM) when a surgical resection was not performed, both according to the International Union Against Cancer (UICC) TNM classification (Sobin et al, 2002). Histological grading was performed following the WHO criteria for squamous cell carcinomas of the oral mucosa (Pindbord et al, 1997). Patient's charts were reviewed for tumour characteristics, risk factors and therapy. For dichotomisation following categories were formed: smoker and non-smoker if having a history of $>10$ or $\leqslant 10$ pack-year during the last 16 years; alcohol consumption and no alcohol consumption if having $>2$ or $\leqslant 2$ standard drinks on every day; moderate or severe comorbidity graded by the Eastern Cooperative Oncology Group (ECOG) $0-1$ vs $2-4$; and age classified as young ( $<60$ years) vs old $(\geqslant 60$ years).

Treatment was defined as the first course of OPSCC-specific treatment of primary tumour and regional lymph nodes. OPSCC stages I and II were treated with radiotherapy or surgery alone upon patient's decision. Advanced cases (stage III-IVa) were allocated to surgery followed by adjuvant radiotherapy or concurrent chemoradiotherapy upon patient's decision. Patients with unresectable disease (stage IVb) were treated with chemoradiotherapy or radiotherapy alone. Patients ineligible for curative therapy (severe comorbidity or rejection of therapy within 6 weeks from date of diagnosis, $n=21$ ), or with insufficient treatment documentation $(n=16)$ were not included in this study.

HPV diagnostics and $16^{\text {INK4a }}$ immunohistochemical staining. Positive HPV status was defined by concomitant positivity for high-risk HPV-DNA detection together with strong, diffuse p16 ${ }^{\text {INK4a }}$ expression in both nucleus and cytoplasm of at least $70 \%$ of tumour cells, as this is considered to indicate truly HPVtransformed lesions (Klussmann et al, 2003a; Reuschenbach et al, 2013; Prigge et al, 2015, 2016). Briefly, DNA extracted from $10 \mu \mathrm{m}$ FFPE tissue sections using the DNeasy Blood and Tissue Kit (Qiagen, Hilden, Germany), corresponding to $\sim 10 \times 10 \mathrm{~mm}$ tumour tissue, was analysed for $\operatorname{HPV}$ genotypes $(16,18,31,33$, $35,39,45,51,52,56,58,59,68,73$ and 82 ) by PCR followed by bead-based hybridisation (Luminex Technology, Multimetrix, Progen, Heidelberg, Germany) (Schmitt et al, 2006; Prigge et al, 2015). p16 ${ }^{\mathrm{INK} 4 \mathrm{a}}$ expression was assessed on $2-3 \mu \mathrm{m}$ FFPE tissue sections using the CINtec Histology kit according to the manufacturer's instructions (Roche mtm Laboratories, Mannheim, Germany).

Statistical analysis. Statistical analysis were performed using SPSS statistical software (IBM SPSS 23.0, Chicago, IL, USA). Risk models were generated with RPA by using the function ctree (conditional inference trees) of the $\mathrm{R}$ (Version 3.2.3) package partykit, Version 1.0-5 (Hothorn, 2015). The stop criterion was set to multiplicityadjusted $P$-values (testtype $=$ 'Bonferroni'). Therapy strategies were categorised into surgical treatments (surgery with or without adjuvant radiation/chemoradiation) and non-surgical treatments (definitive radiation/chemoradiation). Overall survival (OS, calculated from date of histological diagnosis by routine biopsy to date of death) was used to generate survival curves by the Kaplan-Meier method. Follow-up time of event-free patients was not censored. Survival curves were compared using the log-rank test and prognostic impact of the different covariates with hazard ratios (HRs) and 95\% confidence interval for OS was tested by a univariate Cox regression model.

\section{RESULTS}

Patient characteristics. The detailed characteristics of $n=359$ patients included in this study are shown in Supplementary Table 1. Briefly, a positive HPV status was determined for $20.6 \%$ of tumour samples with HPV-type 16 DNA detected in 95.9\%. One sample (1.4\%) each contained HPV-DNA type 26, 18 and 33, respectively. The median age of patients with HPV-related OPSCC was 59.3, and 58.9 years for patients with HPV-negative OPSCC. The TNM classification according to the UICC (Sobin et al, 2002) results in $39(10.9 \%)$ patients with stage I, 33 (9.2\%) with stage II 
and $54(15.0 \%)$ with stage III, which we summarised in the group of less-advanced disease (stage I-III). The majority of patients (232; 64.6\%) belongs to the group of advanced disease (stage IVa-c) with $161(44.8 \%)$ patients with stage IVa, 46 (12.8\%) with stage IVb and $25(7.0 \%)$ with stage IVc.

Univariate analysis of patient characteristics and risk factors as prognostic factors for OS. Except gender, all patient characteristics and risk factors analysed and listed in Supplementary Table 1 had significant impact on OS in univariate analysis by KaplanMeier analysis and with Cox regression (Table 1). Patients with younger age and less comorbidity (ECOG) had better survival than older patients or patients with appreciable comorbidity. The established risk factors for OPSCC smoking and alcohol had negative impact on survival, whereas HPV was associated with better survival. Advanced clinical stage (UICC) and higher T-, N- and M-stages were related with poor survival. Treatment including surgery was associated with better survival in the univariate analysis.

Risk stratification of unselected OPSCC patients according to Ang's prognostic model. We applied the prognostic model proposed by Ang et al (2010) for risk stratification of our unselected patient cohort with OPSCC. All prognostic factors in our data set matched to the classification used by Ang et al with the exception that we included $\mathrm{T} 1$ in the group of small tumours together with T2-T3 tumours. The OS of the low-risk group significantly differs from OS of the intermediate- and high-risk groups (Figure $1, P=0.038$ and $P<0.001$ ). Difference in OS is not significant between intermediate- and high-risk group patients. This is also the case after dividing our unselected cohort for surgical and non-surgical treatment (Figure 1). In the

Table 1. Univariate survival analyses of risk factors for oropharyngeal squamous cell carcinoma patients treated with curative intent

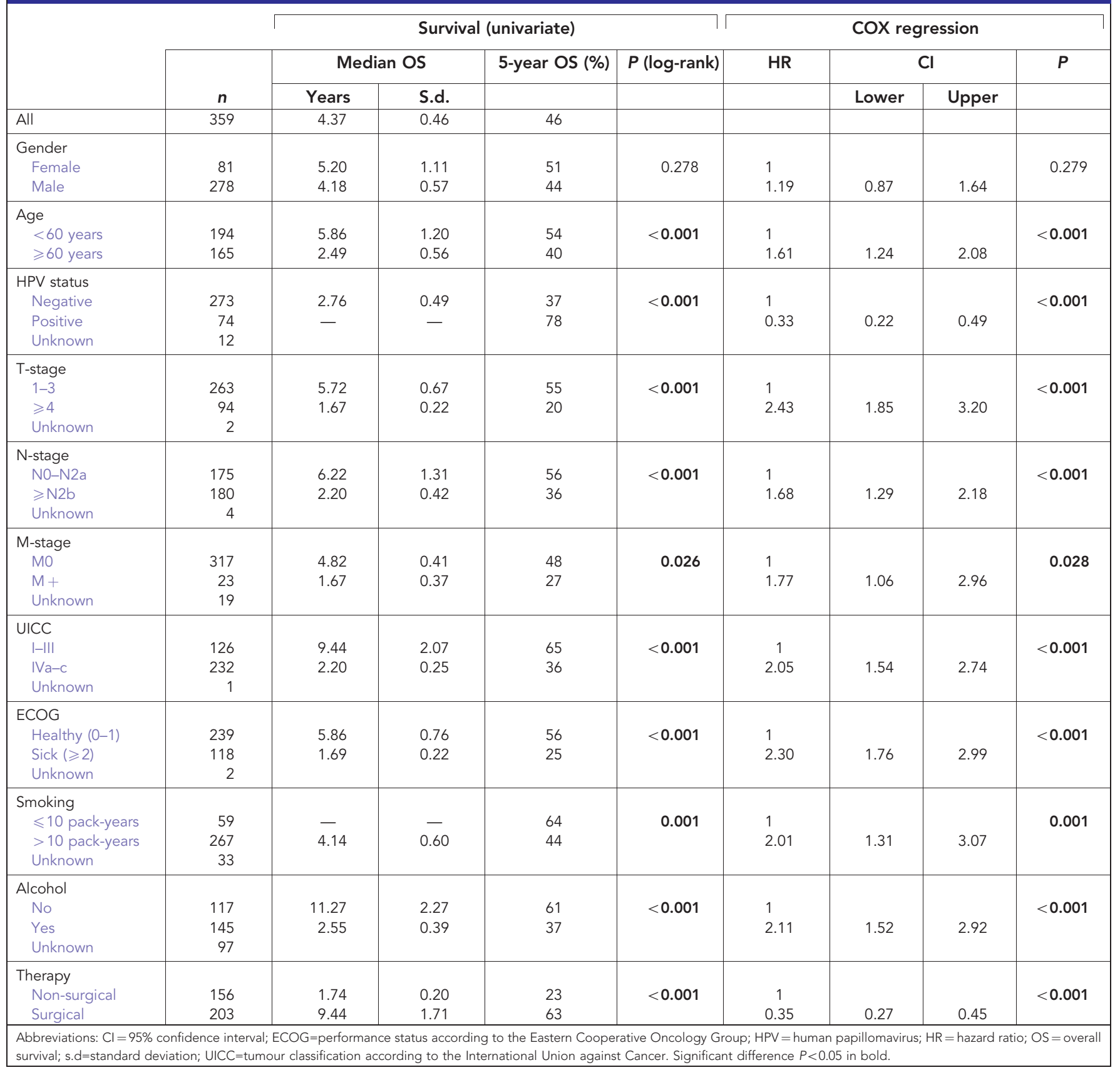


non-surgically treated cohort, OS is not significantly different between patients with predicted low, intermediate and high risk. In the cohort with surgical treatment, OS of low-risk patients is significantly better compared to the groups with intermediate and high risk (Figure $1, P=0.036$ and $P<0.001$ ), but not between groups with predicted high and intermediate risk.
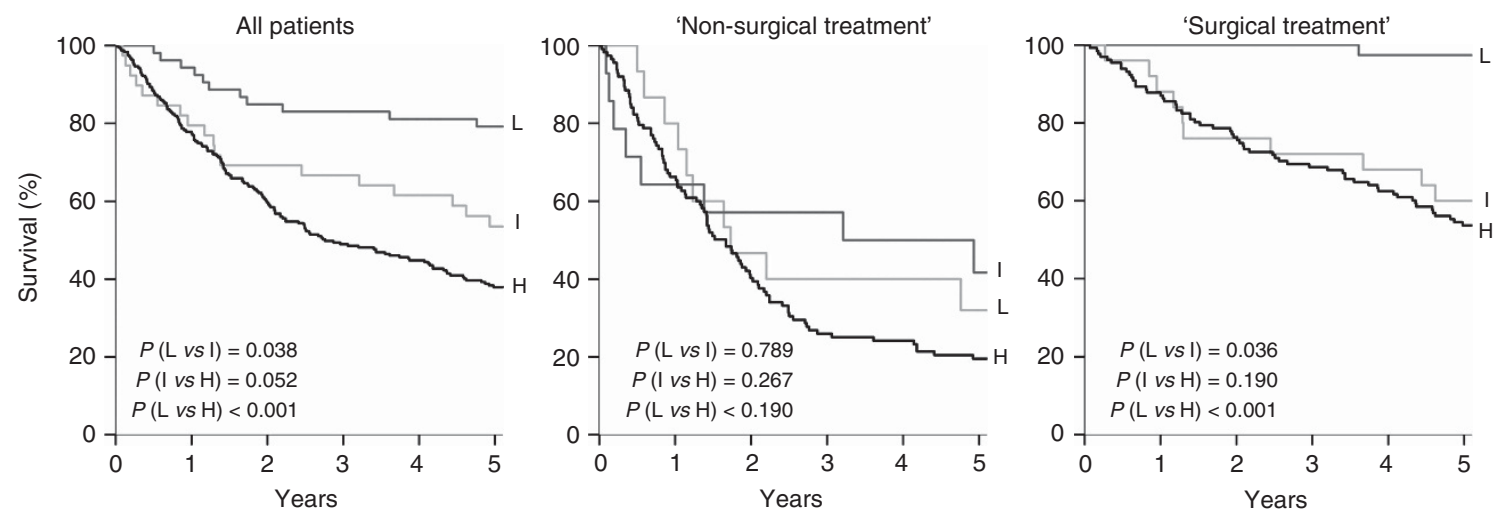

Figure 1. Overall survival of unselected OPSCC patients stratified in low (L)-, intermediate (I)- and high-risk (H) groups according to Ang's prognostic model (Ang et al, 2010) and after stratification for surgical vs non-surgical treatment.

A

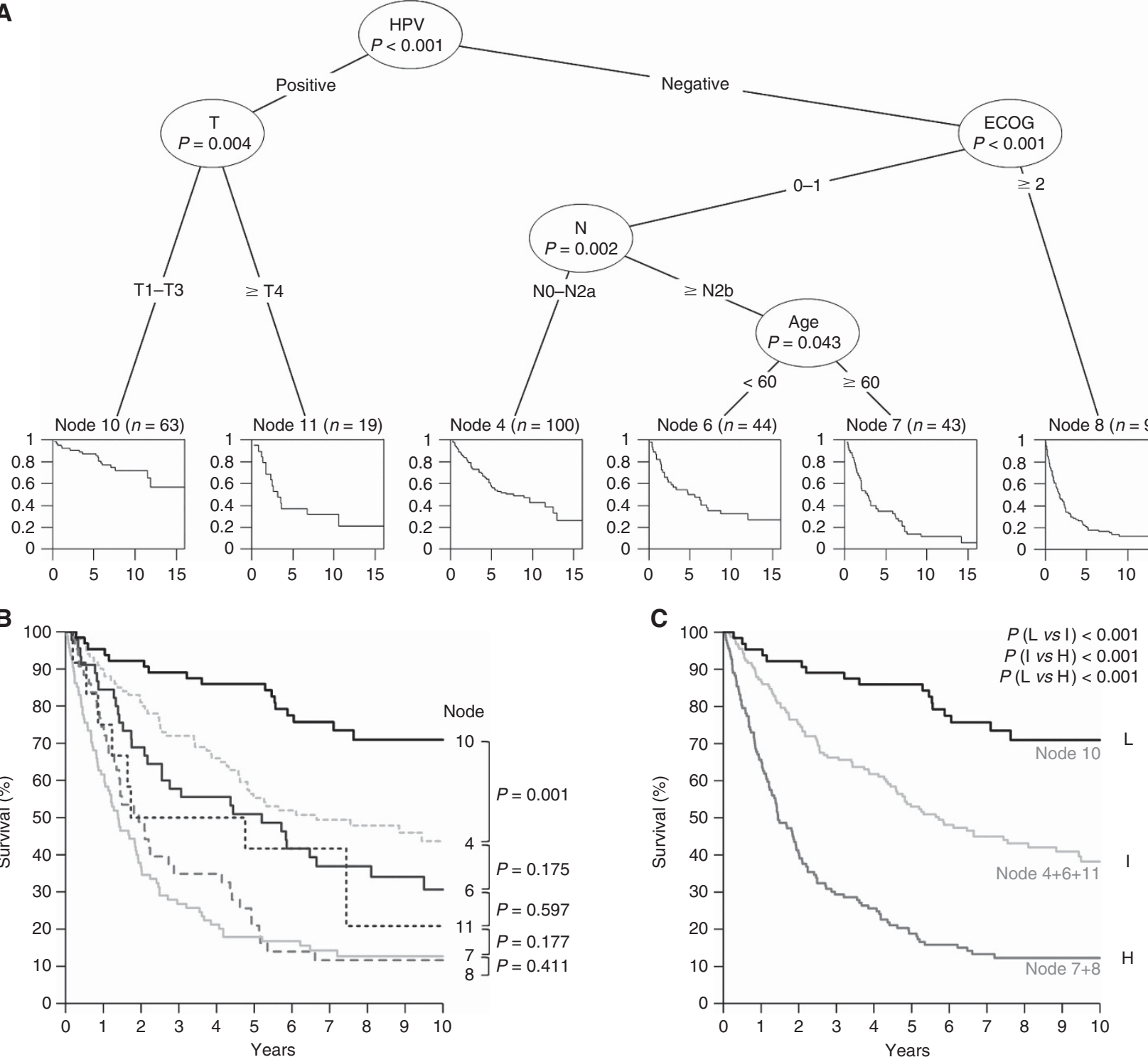

Figure 2. Development of a risk-model for unselected OPSCC. Multivariate analysis of patient characteristics and risk factors by recursive partitioning (A). The order of survival plots has been modified in the conditional interference tree for visualisation. Overall survival of patient groups as determined by recursive partitioning (B) and after dividing into patient groups with low (L: node 10), intermediate (I: node $4+6+11)$ and high $(H$ : node $7+8)$ risk $(C)(n=359)$. 
Multivariate analysis of patient characteristics and risk factors by recursive partitioning. We performed recursive partitioning of our data to build a multivariate risk model for unselected OPSCC. Predictors with significant impact on survival in the univariate analysis were included except UICC stage, alcohol consumption and kind of treatment for following reasons: UICC stage is a composite variable and inclusion would 'double' the influence in the model. The kind of treatment is no independent variable and highly depends on tumour and patient characteristics and patient's decision. In contrast to smoking, fluctuating consumption and different types of drinks (alcohol content and volume) impedes the reliable estimation of the alcohol consumption by questionnaire according to our experience.

The conditional interference tree suggests HPV status to be the most important predictor, followed by comorbidity (ECOG) in patients with HPV-negative, and T-stage in patients with HPVpositive OPSCC (Figure 2A). The group with HPV-negative OPSCC can be further stratified by N-stage and age. Survival plots as end-'Node' of the conditional interference tree are displayed for each risk group. In total six groups with differential survival are formed and arranged in three clusters in Kaplan-Meier survival analysis (Figure 2B). Groups of nodes 7 and 8 represent patients with worst prognosis and cluster together. No significant difference in OS is present between groups of node 4, 6 and 11, and they were combined in the intermediate-risk group (Figure 2C). The resulting survival curves of low-, intermediate- and high-risk patients are significantly different among each other $(P<0.001)$.

On the basis of this finding we rearranged the model shown in Figures 2A and included patient numbers for surgical and nonsurgical treatment (Figure 3). The low-risk group comprises OPSCC

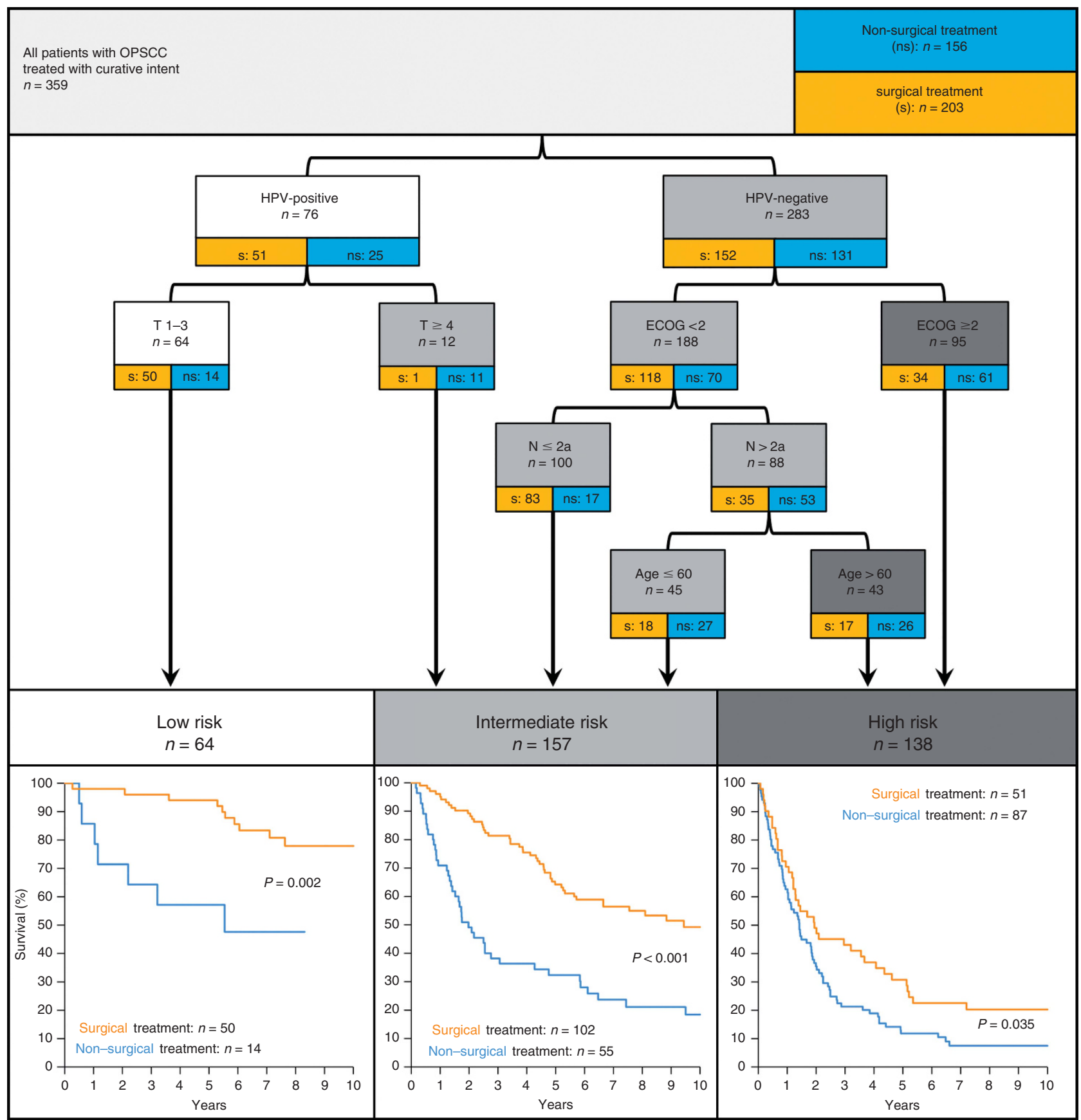

Figure 3. Risk model for OPSCC based on multivariate analysis of patient characteristics and risk factors by recursive partitioning. The OS for risk groups stratified for surgical (orange) vs non-surgical (blue) treatment displayed below respective risk groups. 
Table 2. Cohort characteristics by treatment group

\begin{tabular}{|c|c|c|c|c|c|}
\hline & \multicolumn{2}{|c|}{$\begin{array}{c}\text { Surgical } \\
\text { treatment }\end{array}$} & \multicolumn{2}{|c|}{$\begin{array}{c}\text { Non-surgical } \\
\text { treatment }\end{array}$} & \multirow{2}{*}{$P$-value } \\
\hline & $\%$ & $n$ & $\%$ & $n$ & \\
\hline & 56.5 & 203 & 43.5 & 156 & \\
\hline \multicolumn{6}{|l|}{ Gender } \\
\hline Female & 23.6 & 48 & 21.2 & 33 & \multirow[t]{2}{*}{0.576} \\
\hline Male & 76.4 & 155 & 78.8 & 123 & \\
\hline \multicolumn{6}{|l|}{ Age (years) } \\
\hline$<60$ & 59.1 & 120 & 47.4 & 74 & \multirow[t]{2}{*}{0.028} \\
\hline$\geqslant 60$ & 40.9 & 83 & 52.6 & 82 & \\
\hline \multicolumn{6}{|l|}{ HPV status } \\
\hline Negative & 73.4 & 149 & 79.5 & 124 & \multirow[t]{2}{*}{0.073} \\
\hline Positive & 24.1 & 49 & 16.0 & 25 & \\
\hline \multicolumn{6}{|l|}{ T-stage } \\
\hline T1-3 & 95.1 & 193 & 44.9 & 70 & \multirow[t]{2}{*}{$<0.001$} \\
\hline$\geqslant T 4$ & 4.9 & 10 & 53.8 & 84 & \\
\hline \multicolumn{6}{|l|}{$\mathrm{N}$-stage } \\
\hline N0-N2a & 65.0 & 132 & 27.6 & 43 & \multirow[t]{2}{*}{$<0.001$} \\
\hline$\geqslant N 2 b$ & 35.0 & 71 & 69.9 & 109 & \\
\hline \multicolumn{6}{|l|}{ M-stage } \\
\hline MO & 94.1 & 191 & 80.8 & 126 & \multirow[t]{2}{*}{$<0.001$} \\
\hline $\mathrm{M}+$ & 2.0 & 4 & 12.2 & 19 & \\
\hline \multicolumn{6}{|c|}{ ECOG performance status } \\
\hline $0-1$ & 78.3 & 159 & 51.3 & 80 & \multirow[t]{2}{*}{$<0.001$} \\
\hline$\geqslant 2$ & 20.7 & 42 & 48.7 & 76 & \\
\hline \multicolumn{6}{|l|}{ Smoking } \\
\hline$\leqslant 10$ pack-years & 19.2 & 39 & 12.8 & 20 & \multirow[t]{2}{*}{0.088} \\
\hline$>10$ pack-years & 70.9 & 144 & 78.8 & 123 & \\
\hline \multicolumn{6}{|c|}{$\begin{array}{l}\text { Abbreviation: } \mathrm{HPV}=\text { human papillomavirus; } \mathrm{ECOG}=\text { performance status according to the } \\
\text { Eastern Cooperative Oncology Group. Some variables do not add up to } 100 \% \text { due to } \\
\text { missing data. } \\
\text { a P: Pearson's } \chi^{2} \text {, asymptotic, two-sided. Significant difference } P<0.05 \text { in bold. }\end{array}$} \\
\hline
\end{tabular}

patients with small (T1-T3), HPV-associated tumours. The remaining patients with $\mathrm{HPV}$-associated tumours (and $\mathrm{T} \geqslant 4$ ) are categorised in the intermediate-risk group. The high-risk group is formed only by HPV-negative OPSCC patients with either severe $(\geqslant 2)$ ECOG performance status, or with good performance $(<2)$, but high $\mathrm{N}$-status $(>2 \mathrm{a})$ and older age ( $\geqslant 60$ years). Patients with HPVnegative tumours, less comorbidity, lower $\mathrm{N}$-stage and younger age are categorised in the intermediate-risk group. Significantly better survival of patients treated with surgical compared to non-surgical treatment is observed in the low-, intermediate- and high-risk groups of our unselected cohort (Figure 3).

Multivariate analysis of patient characteristics and risk factors by recursive partitioning in differentially treated patients. We separated our cohort into patients treated with primary surgical intervention $(203 ; 56.5 \%)$ vs non-surgical treatment strategy (156; $43.5 \%)$. The same predictors as for the entire cohort were included in the models (Table 2). For both treatment cohorts HPV status remained a significant predictor in the recursive partitioning, whereas ECOG remained significant only for the surgical treatment cohort (Figure $4 \mathrm{~A}$ and $\mathrm{B}$ ). High-risk subgroups with significantly different survival compared to the intermediate-risk group are defined by both models (Figure 4C: surgical treatment, $P<0.001$; Figure 4D: non-surgical treatment, $P=0.012)$. The lowrisk group was well separated from the intermediate-risk group in the surgical treatment cohort $(P<0.001)$, whereas this separation in the non-surgical treatment cohort only reached 0.05 level of significance $(P=0.044)$. Survival rates and HRs for the unselected cohort and stratified for treatment based on RPA models are summarised in Supplementary Table 2.

\section{DISCUSSION}

Human papillomavirus is the first biomarker for OPSCC to predict outcome beside the classical tumour stages, and has been included in American Joint Committee on Cancer (AJCC) staging systems recently (AJCC, 2017). For guiding therapy to reduce treatment-related morbidity without affecting efficacy, risk groups have to be defined, combining tumour stage, HPV and possible other prognosticators. Ang et al (2010) published the first model in this regard using RPA. It was developed from a study population comparing accelerated fractionation radiotherapy with standard fractionation radiotherapy combined with concurrent cisplatin therapy. HPV status, pack-years of tobacco smoking, tumour stage and nodal stage were most important and used to classify patients into risk groups with low, intermediate and high risk of death (Ang et al, 2010). Inclusion criteria for this prospective study were stage III or IV OPSCC and Zubrod's (ECOG) performance status score $0-1$. Therefore, patients were highly selected and/or study indicates that this model is unsuited for unselected, primary surgically treated patient (Figure 1).

We found HPV status, tobacco smoking, tumour and nodal stage, as well as age and performance status to be the most important factors for survival in univariate analysis, and except smoking all factors remained significant predictors in the multivariate RPA modelling. In a recent study, $\mathrm{T}$-stage but not $\mathrm{N}$-stage was associated with $\mathrm{OS}$ in HPV-positive OPSCC (Amini et al, 2016), which is confirmed by our model. In the same study, AJCC stage was strongly associated with OS in HPV-negative patients but poorly associated with OS in HPVpositive OPSCC, supporting the need to adapt staging for HPV status (Amini et al, 2016). In a recently published study, refinement of the AJCC/UICC staging was achieved for HPV-related OPCC $(n=573)$ of non-surgically treated patients. T- and $\mathrm{N}$-stage emerged as most important prognostic factors for HPV-related OPSCC (Huang et al, 2015), which was subsequently validated with 8803 HPV-positive OPSCC and supports a risk-adapted staging schema for OPSCC (Horne et al, 2016).

The model developed by Ang et al (2010) was tested in two retrospective series of stage III-IV OPSCC treated with either surgery followed by radiotherapy or chemoradiation with/ without induction chemotherapy (Bossi et al, 2014). In the lowand intermediate-risk groups, better survival was observed for nonsurgical $v s$ open-surgical approach. An important drawback of this study is that patients were treated with surgery between 1990 and 1999, whereas between 2004 and 2010 all patients with locally advanced OPSCC were treated non-surgically (Bossi et al, 2014). The surgical group was not treated in line with nowadays standards including adjuvant chemotherapy for high-risk cases and surgical approaches have improved during last years. Therefore, comparing OS of patients in both cohorts might not be appropriate. In our unselected cohort, we observed better survival for patients treated with upfront surgery in the low- and intermediate-risk groups. However, in addition to unknown factors not covered by our model, this might be confounded by patient selection.

Noteworthy, smoking has no impact in the RPA models for our cohort, but is a major factor in the risk model predicted by Ang et al (2010). In accordance to literature, smoking is less frequent in patients with HPV-associated OPSCC in the selected cohort used by Ang et al (2010) (51 vs 74\%), and also in our cohort (49 vs 91\%, $P<0.001)$. In our model, smoking might be cancelled due to the high rate of smokers in the HPV-negative group. Furthermore, smoking might influence radiosensitivity, for example, via reducing tumour oxygenation by a rise in carboxyhaemoglobin level in smokers and its prognostic impact could be less important after primary surgically treatment.

For two unselected cohorts testing risk models by RPA, most important factors were HPV status, nodal stage, comorbidity and T-stage (Rietbergen et al, 2013, 2015). However, in contrast to our 
A

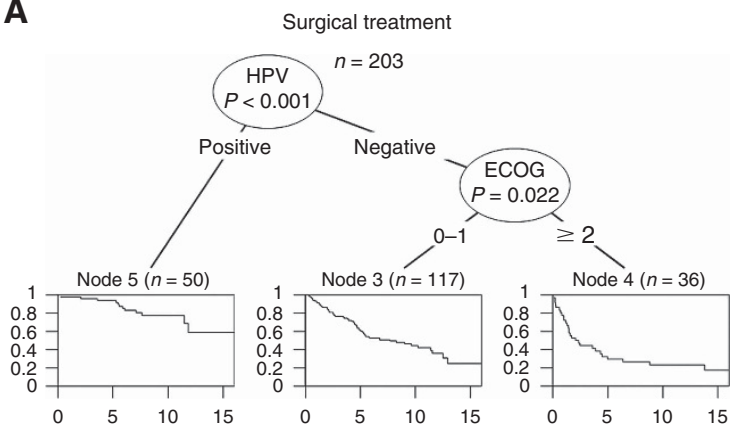

C

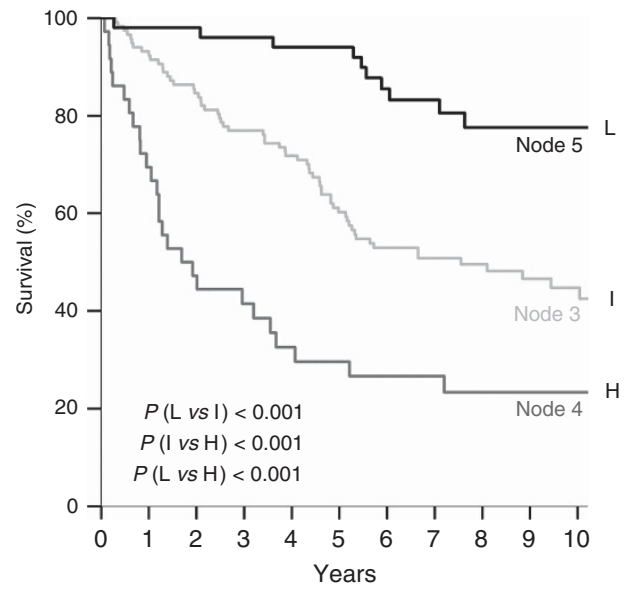

B

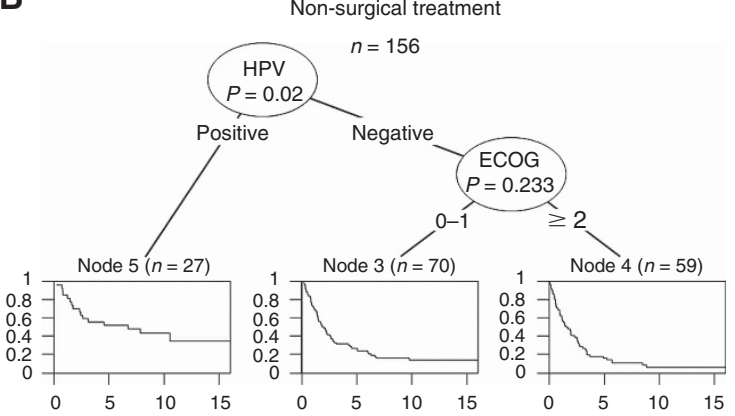

D

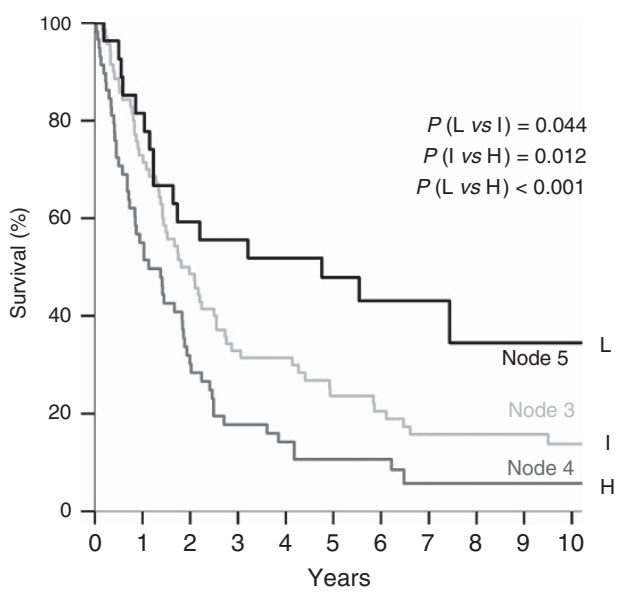

Figure 4. Risk models for differentially treated patients. Multivariate analysis of patient characteristics and risk factors by recursive partitioning in OPSCC patients treated with surgery alone or in combination with any adjuvant therapy (A) or without any surgical intervention (B). The order of survival plots has been modified in the conditional interference tree for visualisation. Overall survival of patients with low (L: node 5), intermediate (I: node 3) and high risk ( $\mathrm{H}$ : node 4) treated with (C) or without any surgical intervention (D) as determined by recursive partitioning.

study, treatment was primary chemoradiotherapy in $70 \%$ of the cases (503 out of 723 and 164 out of 235) in both cohorts. Compared to our study comorbidity substitutes T-stage as the only predictor in the HPV-positive arm, whereas T-stage appears at the bottom of the decision tree for HPV-negative OPSCC, which might constitute to the different treatment regimens. In relation to ACE27 the ECOG comorbidity classification system is less complex. In the abovementioned model, the ACE27 score probably cover the influence of age on comorbidity and might explain appearance of age at the bottom of the HPV-negative arm in our model.

In another study, patients treated with definitive radiotherapy or chemoradiation were investigated using Cox proportional hazard regression. HPV status was the most important predictor followed by pre-radiotherapy haemoglobin level, T-stage, gender, N-stage, comorbidity and smoking in descending order (Rios Velazquez et al, 2014). For most factors, this ranking fits to our model, although the study populations differ in treatment. Furthermore, we found HPV-positive OPSCC to be associated with low T-stage (T1-2: 68 vs 47\%, $P=0.001$ ) and advanced N-stage ( $>$ N0: 86 vs $69 \%, P=0.003$ ), in consistence to literature (Keane et al, 2015). This was not the case in the mentioned study (Rios Velazquez et al, 2014) and might explain potential impact of other factors in this model, besides differences in treatment.

Only HPV status and ECOG remained significant predictors in our RPA after stratification for surgical $v s$ non-surgical treatment. Treatment decision, which is either surgical or non-surgical in Germany and many other European countries, is based on tumour characteristics and comorbidity (indicated by differential distribution of these factors in both treatment groups (Table 2)). Therefore, these predictors might not appear in the RPA modelling in each subcohort. In contrast, no significant difference is seen regarding risk factors with high impact on OS, such as HPV and smoking (Table 2), which are unconsidered for treatment decision today. Although treatment was independent from the proposed risk groups, patients with beneficial OS were selected in all-risk groups by the surgical approach compared to non-surgical treatment, indicating an advantage of upfront surgery for certain patients (Figure 3 ). This is supported by recent data showing that surgical resection is an effective therapy for early and intermediate OPSCC (Kass et al, 2016). In HPV-related OPSCC, trends are heading towards treatment de-escalation. Nevertheless, patient characteristics such as age and comorbidity should be considered in models destined for adjustment of treatment as they influence OS regardless of the tumour and its treatment.

In summary, besides ECOG, HPV status is the major predictor in our RPA modelling for differentially treated patient cohorts and has significant impact on survival in surgically and non-surgically treated patients. This shows that risk modelling for OPSCC has to be adapted for the respective treatment regimens in the context of de-escalation studies.

\section{CONFLICT OF INTEREST}

MvKD was shareholder and member of the supervisory board of mtm Laboratories, Heidelberg, Germany. The remaining authors declare no conflict of interest.

\section{REFERENCES}

AJCC (2017) AJCC Cancer Staging Manual, Amin MB, Edge S, Greene F, Byrd DR, Brookland RK, Washington MK, Gershenwald JE, Compton CC, Hess KR, Sullivan DC, Jessup JM, Brierley JD, Gaspar LE, Schilsky RL, 
Balch CM, Winchester DP, Asare EA, Madera M, Gress DM, Meyer LR (eds). HPV-Mediated (p16+) Oropharyngeal Cancer, Chapter 10. Springer International Publishing: New York, NY, USA, pp 113-136.

Amini A, Jasem J, Jones BL, Robin TP, Mcdermott JD, Bhatia S, Raben D, Jimeno A, Bowles DW, Karam SD (2016) Predictors of overall survival in human papillomavirus-associated oropharyngeal cancer using the National Cancer Data Base. Oral Oncol 56: 1-7.

Ang KK, Harris J, Wheeler R, Weber R, Rosenthal DI, Nguyen-Tan PF, Westra WH, Chung CH, Jordan RC, Lu C, Kim H, Axelrod R, Silverman CC, Redmond KP, Gillison ML (2010) Human papillomavirus and survival of patients with oropharyngeal cancer. N Engl J Med 363: 24-35.

Bossi P, Orlandi E, Miceli R, Perrone F, Guzzo M, Mariani L, Granata R, Locati L, Fallai C, Cortelazzi B, Pilotti S, Scaramellini G, Gloghini A, Licitra L (2014) Treatment-related outcome of oropharyngeal cancer patients differentiated by HPV dictated risk profile: a tertiary cancer centre series analysis. Ann Oncol 25: 694-699.

Chaturvedi AK, Engels EA, Pfeiffer RM, Hernandez BY, Xiao W, Kim E, Jiang B, Goodman MT, Sibug-Saber M, Cozen W, Liu L, Lynch CF, Wentzensen N, Jordan RC, Altekruse S, Anderson WF, Rosenberg PS, Gillison ML (2011) Human papillomavirus and rising oropharyngeal cancer incidence in the United States. J Clin Oncol 29: 4294-4301.

Fakhry C, Zhang Q, Nguyen-Tan PF, Rosenthal D, El-Naggar A, Garden AS, Soulieres D, Trotti A, Avizonis V, Ridge JA, Harris J, Le QT, Gillison M (2014) Human papillomavirus and overall survival after progression of oropharyngeal squamous cell carcinoma. J Clin Oncol 32: 3365-3373.

Gillison ML, Chaturvedi AK, Anderson WF, Fakhry C (2015) Epidemiology of human papillomavirus-positive head and neck squamous cell carcinoma. J Clin Oncol 33: 3235-3242.

Granata R, Miceli R, Orlandi E, Perrone F, Cortelazzi B, Franceschini M, Locati LD, Bossi P, Bergamini C, Mirabile A, Mariani L, Olmi P, Scaramellini G, Potepan P, Quattrone P, Ang KK, Licitra L (2012) Tumor stage, human papillomavirus and smoking status affect the survival of patients with oropharyngeal cancer: an Italian validation study. Ann Oncol 23: $1832-1837$.

Hayes C (2015) HPV - changing the face of head and neck cancer and dental societies' responsibilities. Todays FDA 27: 38-39.

Horne ZD, Glaser SM, Vargo JA, Ferris RL, Balasubramani GK, Clump DA, Heron DE, Beriwal S (2016) Confirmation of proposed human papillomavirus risk-adapted staging according to AJCC/UICC TNM criteria for positive oropharyngeal carcinomas. Cancer 122: 2021-2030.

Hothorn TZA (2015) partykit: a modular toolkit for recursive partytioning in R. J Mach Learn Res 16: 3905-3909.

Huang SH, Xu W, Waldron J, Siu L, Shen X, Tong L, Ringash J, Bayley A, Kim J, Hope A, Cho J, Giuliani M, Hansen A, Irish J, Gilbert R, Gullane P, Perez-Ordonez B, Weinreb I, Liu FF, O'sullivan B (2015) Refining American Joint Committee on Cancer/Union for International Cancer Control TNM stage and prognostic groups for human papillomavirusrelated oropharyngeal carcinomas. J Clin Oncol 33: 836-845.

Kass JI, Giraldez L, Gooding W, Choby G, Kim S, Miles B, Teng M, Sikora AG, Johnson JT, Myers EN, Duvvuri U, Genden EM, Ferris RL (2016) Oncologic outcomes of surgically treated early-stage oropharyngeal squamous cell carcinoma. Head Neck 38: 1467-1471.

Keane FK, Chen YH, Neville BA, Tishler RB, Schoenfeld JD, Catalano PJ, Margalit DN (2015) Changing prognostic significance of tumor stage and nodal stage in patients with squamous cell carcinoma of the oropharynx in the human papillomavirus era. Cancer 121: 2594-2602.

Klussmann JP, Gultekin E, Weissenborn SJ, Wieland U, Dries V, Dienes HP, Eckel HE, Pfister HJ, Fuchs PG (2003a) Expression of p16 protein identifies a distinct entity of tonsillar carcinomas associated with human papillomavirus. Am J Pathol 162: 747-753.

Klussmann JP, Weissenborn SJ, Wieland U, Dries V, Eckel HE, Pfister HJ, Fuchs PG (2003b) Human papillomavirus-positive tonsillar carcinomas: a different tumor entity? Med Microbiol Immunol 192: 129-132.

Klussmann JP, Weissenborn SJ, Wieland U, Dries V, Kolligs J, Jungehuelsing M, Eckel HE, Dienes HP, Pfister HJ, Fuchs PG (2001) Prevalence, distribution, and viral load of human papillomavirus 16 DNA in tonsillar carcinomas. Cancer 92: 2875-2884.
Lybak S, Ljokjel B, Haave H, Karlsdottir A, Vintermyr OK, Aarstad HJ (2017) Primary surgery results in no survival benefit compared to primary radiation for oropharyngeal cancer patients stratified by high-risk human papilloma virus status. Eur Arch Otorhinolaryngol 274: 477-487.

Maxwell JH, Grandis JR, Ferris RL (2016) HPV-associated head and neck cancer: unique features of epidemiology and clinical management. Annu Rev Med 67: 91-101.

Mirghani H, Amen F, Blanchard P, Moreau F, Guigay J, Hartl DM, Lacau St Guily J (2015) Treatment de-escalation in HPV-positive oropharyngeal carcinoma: ongoing trials, critical issues and perspectives. Int J Cancer 136: 1494-1503.

Pindbord JJ, RP, Smith CJ, Van Der Waal I (1997) Histological Typing of Cancer and Precancer of the Oral Mucosa. 2nd edn, Springer: Berlin, New York.

Prigge ES, Arbyn M, Von Knebel Doeberitz M, Reuschenbach M (2016) Diagnostic accuracy of p16INK4a immunohistochemistry in oropharyngeal squamous cell carcinomas: a systematic review and meta-analysis. Int J Cancer 140(5): 1186-1198.

Prigge ES, Toth C, Dyckhoff G, Wagner S, Muller F, Wittekindt C, Freier K, Plinkert P, Hoffmann J, Vinokurova S, Klussmann JP,

Von Knebel Doeberitz M, Reuschenbach M (2015) p16(INK4a)/Ki-67 co-expression specifically identifies transformed cells in the head and neck region. Int J Cancer 136: 1589-1599.

Reuschenbach M, Roos J, Panayotopoulos D, Baldus SE, Schnurch HG, Berger A, Petry KU, Durst M, Seiz M, Von Knebel Doeberitz M, Hampl M (2013) Characterization of squamous cell cancers of the vulvar anterior fourchette by human papillomavirus, p16INK4a, and p53. J Low Genit Tract Dis 17: 289-297.

Rietbergen MM, Brakenhoff RH, Bloemena E, Witte BI, Snijders PJ, Heideman DA, Boon D, Koljenovic S, Baatenburg-de Jong RJ, Leemans CR (2013) Human papillomavirus detection and comorbidity: critical issues in selection of patients with oropharyngeal cancer for treatment de-escalation trials. Ann Oncol 24: 2740-2745.

Rietbergen MM, Witte BI, Velazquez ER, Snijders PJ, Bloemena E, Speel EJ, Brakenhoff RH, Kremer B, Lambin P, Leemans CR (2015) Different prognostic models for different patient populations: validation of a new prognostic model for patients with oropharyngeal cancer in Western Europe. $\mathrm{Br} J$ Cancer 112: 1733-1736.

Rios Velazquez E, Hoebers F, Aerts HJ, Rietbergen MM, Brakenhoff RH, Leemans RC, Speel EJ, Straetmans J, Kremer B, Lambin P (2014) Externally validated HPV-based prognostic nomogram for oropharyngeal carcinoma patients yields more accurate predictions than TNM staging. Radiother Oncol 113: 324-330.

Ritchie JM, Smith EM, Summersgill KF, Hoffman HT, Wang D, Klussmann JP, Turek LP, Haugen TH (2003) Human papillomavirus infection as a prognostic factor in carcinomas of the oral cavity and oropharynx. Int J Cancer 104: 336-344.

Schmitt M, Bravo IG, Snijders PJ, Gissmann L, Pawlita M, Waterboer T (2006) Bead-based multiplex genotyping of human papillomaviruses. J Clin Microbiol 44: 504-512.

Sobin LH, Wittekind C, International Union Against Cancer (2002) TNM: Classification of Malignant Tumours. Wiley-Liss: New York, NY, USA.

Stanley M (2012) Perspective: vaccinate boys too. Nature 488: S10.

Tinhofer I, Johrens K, Keilholz U, Kaufmann A, Lehmann A, Weichert W, Stenzinger A, Stromberger C, Klinghammer K, Becker ET, Dommerich S, Stolzel K, Hofmann VM, Hildebrandt B, Moser L, Ervens J, Bottcher A, Albers A, Stabenow R, Reinecke A, Budach V, Hoffmeister B, Raguse JD (2015) Contribution of human papilloma virus to the incidence of squamous cell carcinoma of the head and neck in a European population with high smoking prevalence. Eur J Cancer 51: 514-521.

Vokes EE, Agrawal N, Seiwert TY (2015) HPV-associated head and neck cancer. J Natl Cancer Inst 107: djv344.

This work is published under the standard license to publish agreement. After 12 months the work will become freely available and the license terms will switch to a Creative Commons AttributionNonCommercial-Share Alike 4.0 Unported License. 